\title{
Corrigendum: Impulsivity Derived From the Dark Side: Neurocircuits That Contribute to Negative Urgency
}

\author{
Eric P. Zorrilla ${ }^{1 *}$ and George F. Koob ${ }^{2}$ \\ ${ }^{1}$ Department of Neuroscience, The Scripps Research Institute, La Jolla, CA, United States, ${ }^{2}$ Neurobiology of Addiction \\ Section, Intramural Research Program, National Institute on Drug Abuse, Baltimore, MD, United States
}

Keywords: negative urgency, impulsivity, compulsive drug use, negative affect, withdrawal, substance or alcohol use disorder, orbitofrontal cortex, extended amygdale

\section{A Corrigendum on}

Impulsivity Derived From the Dark Side: Neurocircuits That Contribute to Negative Urgency by Zorrilla, E. P., and Koob, G. F. (2019). Front. Behav. Neurosci. 13:136. doi: $10.3389 /$ fnbeh.2019.00136

In the original article there was an error. The reference for Um et al. (2019) was incorrectly cited.

A correction has been made to the section Negative Urgency and Addiction: Tobacco, Alcohol, Cocaine, Pathological Gambling, and Food subsection Alcohol, paragraph seven:

"A study of 675 community-dwelling adults in the Rockland Project used structural equation modeling path analysis to evaluate the mediating vs. moderating roles of urgency in the relationship between depression and problematic alcohol or cannabis use. Negative urgency, not positive urgency, was a unique mediator of the relationships between depressive symptoms and both problematic alcohol use and problematic cannabis use. Additionally, negative urgency moderated the relationship between depressive symptoms and problematic cannabis use. Specifically, at low levels of negative urgency, depressive symptoms predicted less problematic cannabis use, whereas at high levels of negative urgency, depressive symptoms predicted greater cannabis use. The authors concluded that despite being statistically correlated with each another, negative and positive urgency had distinct influences on the relationship between depressive symptoms and alcohol and cannabis use, with negative urgency having unique predictive significance (Um et al., 2019a).”

Additionally, a correction has been made to the section Neurocircuitry Implicated in Negative Urgency and Addiction, paragraph one:

"Neurobiological data on negative urgency are limited to date, but negative urgency has been hypothesized to reflect impairments in the "top-down" cortical control over both basal ganglia and extended amygdala function (Figure 2). This topic was very recently reviewed in detail (Um et al., 2019b) so we only briefly discuss key findings here. Most, if not all, of the data are derived from human imaging studies. Deficient top-down control has been hypothesized to reflect a loss of control over pathological habits that involve basal ganglia and extended amygdala processing (Robbins and Everitt, 1999; Everitt and Robbins, 2005; George et al., 2007; Belin et al., 2013) and greater attention to, incentive salience of, or cognitive resource interference from emotion-evoking stimuli. Consequently, in the presence of negative emotion, there is a reduction of inhibitory control over potentially detrimental actions and habits, the latter reflecting increased behavioral control by the dorsolateral striatum (Everitt and Robbins, 2005; Belin and Everitt, 2008; Belin et al., 2013; Giuliano et al., 2019). These biases putatively reflect alterations of the structure, function, or connectivity of orbitofrontal cortex (OFC)/ventromedial 
prefrontal cortex (vmPFC) projections to the basal ganglia and extended amygdala (Cyders and Smith, 2008; Robbins et al., 2012; Smith and Cyders, 2016; Figure 2).”

\section{REFERENCES}

Belin, D., Belin-Rauscent, A., Murray, J. E., and Everitt, B. J. (2013). Addiction: failure of control over maladaptive incentive habits. Curr. Opin. Neurobiol. 23, 564-572. doi: 10.1016/j.conb.2013.01.025

Belin, D., and Everitt, B. J. (2008). Cocaine seeking habits depend upon dopaminedependent serial connectivity linking the ventral with the dorsal striatum. Neuron 57, 432-441. doi: 10.1016/j.neuron.2007.12.019

Cyders, M. A., and Smith, G. T. (2008). Emotion-based dispositions to rash action: positive and negative urgency. Psychol. Bull. 134, 807-828. doi: $10.1037 / \mathrm{a} 0013341$

Everitt, B. J., and Robbins, T. W. (2005). Neural systems of reinforcement for drug addiction: from actions to habits to compulsion. Nat. Neurosci. 8, 1481-1489. doi: $10.1038 / \mathrm{nn} 1579$

George, O., Ghozland, S., Azar, M. R., Cottone, P., Zorrilla, E. P., Parsons, L. H., et al. (2007). CRF-CRF $F_{1}$ system activation mediates withdrawalinduced increases in nicotine self-administration in nicotine-dependent rats. Proc. Natl. Acad. Sci. U S A 104, 17198-17203. doi: 10.1073/pnas.07075 85104

Giuliano, C., Belin, D., and Everitt, B. J. (2019). Compulsive alcohol seeking results from a failure to disengage dorsolateral striatal control over behavior. J. Neurosci. 39, 1744-1754. doi: 10.1523/jneurosci.2615-18.2018
The authors apologize for this error and state that this does not change the scientific conclusions of the article in any way. The original article has been updated.

Robbins, T. W., and Everitt, B. J. (1999). Drug addiction: bad habits add up. Nature 398, 567-570. doi: 10.1038/19208

Robbins, T. W., Gillan, C. M., Smith, D. G., de Wit, S., and Ersche, K. D. (2012). Neurocognitive endophenotypes of impulsivity and compulsivity: towards dimensional psychiatry. Trends Cogn. Sci. 16, 81-91. doi: 10.1016/j.tics.2011.11.009

Smith, G. T., and Cyders, M. A. (2016). Integrating affect and impulsivity: the role of positive and negative urgency in substance use risk. Drug Alcohol Depend. 163, S3-S12. doi: 10.1016/j.drugalcdep.2015.08.038

Um, M., Hershberger, A. R., and Cyders, M. A. (2019a). The relationship among depressive symptoms, urgency, and problematic alcohol and cannabis use in community adults. Addict. Behav. 88, 36-42. doi: 10.1016/j.addbeh.2018.08.009

Um, M., Whitt, Z. T., Revilla, R., Hunton, T., and Cyders, M. A. (2019b). Shared neural correlates underlying addictive disorders and negative urgency. Brain. Sci. 9:E36. doi: 10.3390/brainsci9020036

Copyright (c) 2019 Zorrilla and Koob. This is an open-access article distributed under the terms of the Creative Commons Attribution License (CC BY). The use, distribution or reproduction in other forums is permitted, provided the original author(s) and the copyright owner(s) are credited and that the original publication in this journal is cited, in accordance with accepted academic practice. No use, distribution or reproduction is permitted which does not comply with these terms. 